\title{
An Eye Simulation for Training in the Use of Ophthalmologic Equipment and Corneal Foreign Body Removal Techniques
}

This article was published in the following Dove Press journal:

Advances in Medical Education and Practice

\author{
Linda Brindley Thompson (D) \\ Department of Emergency Medicine, \\ University of Alabama at Birmingham \\ Birmingham, Alabama, USA
}

Purpose: This simulation curriculum is structured to teach the use of common eye assessment equipment and corneal foreign removal techniques using harvested cow eye models, the ophthalmologic burr, and the hollow-bore needle.

Methods: This curriculum involves using one self-assessment (SA) station and three skills stations. The skill stations teach the use of the iCareTonometer, Woods Lamp, and Slit Lamp, and train corneal foreign body removal using a burr and hollow-bore needle.

Results: Sixteen first, second, and third-year (PGY 1-3) residents of the University of Alabama at Birmingham (UAB) Emergency Medicine participated. 100\% indicated this should be an annual training with $87 \%$ indicating this was highly realistic. There was a $44 \%$ Pre-Sim to $94 \%$ Post-Sim SA for improvement with iCareTonometer skill. There was a 7\% Pre-Sim to $100 \%$ post-Sim SA for improvement with Slit-Lamp skill. There was a 32\% Pre-Sim to $100 \%$ Post-Sim SA improvement with Woods Lamp skill. For CFB removal, there was a 13\% Pre-Sim to 94\% Post-Sim SA for improvement with burr and hollow-bore needle skill.

Conclusion: The self-assessments indicated that this simulation was successful in leading these emergency medicine residents to attaining enhanced self-assessed competencies in the use of common eye assessment equipment and for corneal foreign body removal using the burr and the hollow-bore needle. To establish curriculum globalization, reliability, and competency, larger test groups will have to be studied and objective qualified testers will need to assess competencies.

Keywords: ophthalmologic burr, slit-lamp, iCare Tonometer, Woods Lamp, harvested cow eyes, metal-grind foreign bodies

\section{Introduction}

The most recent statistics have shown that in the United States over 11 million emergency department (ED) visits involve ocular problems ${ }^{1}$ with the overall ED visits in the last decade "outpacing growth of the general population". ${ }^{2}$ In addition, corneal foreign bodies (CFBs) account for approximately $35 \%$ of all eye injuries. ${ }^{3}$ Given these numbers, training emergency medicine (EM) residents in the use of common eye assessment equipment (EAE) and for CFB removal should be a part of EM education. A literature search would indicate that these skills have not typically been well covered in EM curricula, ${ }^{4-9}$ leading to a gap in education. By providing a structured approach to teaching the use of common EAE, this SIM can lead to closing this EM educational gap.

In addition, several eye SIM curricula have been described in the education literature. ${ }^{10-17}$ These curricula have not focused on specific instruction in the use of
Correspondence: Linda Brindley Thompson Department of Emergency Medicine, University of Alabama at Birmingham, 619

19th Street South, OHB 246B, Birmingham, AL 35249-7013, USA

Tel +I 2059759358

Email lbthompson@uabmc.edu 
the iCareTonometer, the Woods Lamp, the Slit Lamp, and the ophthalmologic burr/hollow bore needle for CFB removal. Of the CFB removal curricula, the prior course designs have lacked realism due to the unnatural artificial eye models (agar trays, gel, glass spheres, cardboard) ${ }^{10-14}$ and the uncommon CFBs (wax, ground pepper, peppercorn, mustard seeds). ${ }^{10,12-14,16}$

This SIM is more realistic than previously described in the literature. The eye models used are created from harvested cow eyes embedded with metal grinds, a common industrial $\mathrm{CFB} .{ }^{18}$ To add to the realism, these eye models are mounted in Styrofoam heads which has the additional benefit of enabling these models to be easily used with the EAE.

\section{Materials and Methods}

The Institutional Review Board at the University of Alabama at Birmingham (UAB) reviewed this SIM and determined it to qualify as an exemption as defined in 45CFR46.101(b), paragraph 1. Prior to the beginning of the Sim, each potential participant was provided information concerning the Sim objectives, and given the option to participate or to decline involvement. The participants whose images are featured have provided written informed consent agreeing to allow their images to be published.

\section{Curricular Design}

Figure 1-2. This curriculum involved creating realistic eye simulation models using harvested cow eyes and metal grinds as CFBs. The creation of the eye models and CFBs were completed before the day of the simulation. The harvested cow eyes were purchased from the web-based company www.homesciencetools.com. (Cost: \$2. 56/eye) The eyes were placed in egg crates and a metal grinder was used to produce metal grinds from a metal strip. This technique created hot grinds that were able to adhere to each cow cornea. These eyes were then mounted in the eye sockets of the Styrofoam head molds purchased from Century Novelty. (Cost: \$5. 22/ head). The Styrofoam molds had eye-sockets created for these cow eyes by using a spoon to scoop out the Styrofoam from the eye areas on the face of these molds. In addition, other materials were acquired before the Simulation. A box of Fluorescence strips and 2 Algerbrush II burrs were purchased from Amazon.com for \$22.00/box and \$85.50/burr, respectively. The Slit-Lamp, the Woods Lamp, the iCare Tonometer, disposable gloves, and hollow-bore needles of varying sizes (18-G, 20-G, 25-G) were borrowed from the ED. The course instructors were Emergency Medicine Board Certified UAB

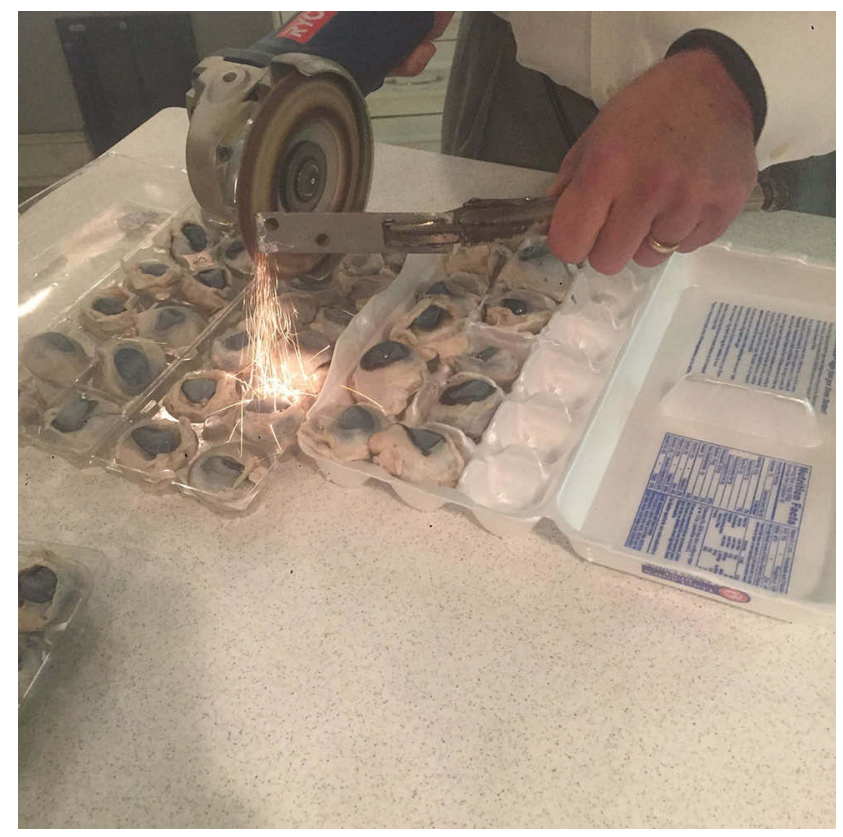

Figure I The creation of the harvested cow eye models with metal grinds.

School of Medicine faculty. On the day of the simulation, four stations were created.

\section{Station I}

Figure 3. This is the Pre- and Post-Sim Self-Assessment Station. The simulation started and ended at this station. This station required a table, chairs, and printed pre- and post-test assessments for each participant. All trainees and instructors gathered at the start of the Sim for instruction. A pre-test self-assessment questionnaire was completed. These self-assessments were focused on a trainee's current knowledge, skills, and attitudes regarding the use of the Slit-lamp, the Woods lamp, the iCareTonometer, and the use of the ophthalmological burr and hollow bore needle for removal of corneal foreign bodies. Then, the trainees were divided into three groups. Each group comprised PGY 1-3 Emergency Medicine residents. Each participant was given one Styrofoam head with two harvested cow eyes as their personal sim-model. At the completion of all skills stations, the instructors and trainees returned to this station to complete a post-simulation selfassessment and course evaluation. The self-assessments were targeted at individual self-perception concerning their post-simulation confidence and competence in using the aforementioned equipment, and in their ability to remove CFBs. The course evaluations were focused on the training value and realism. 


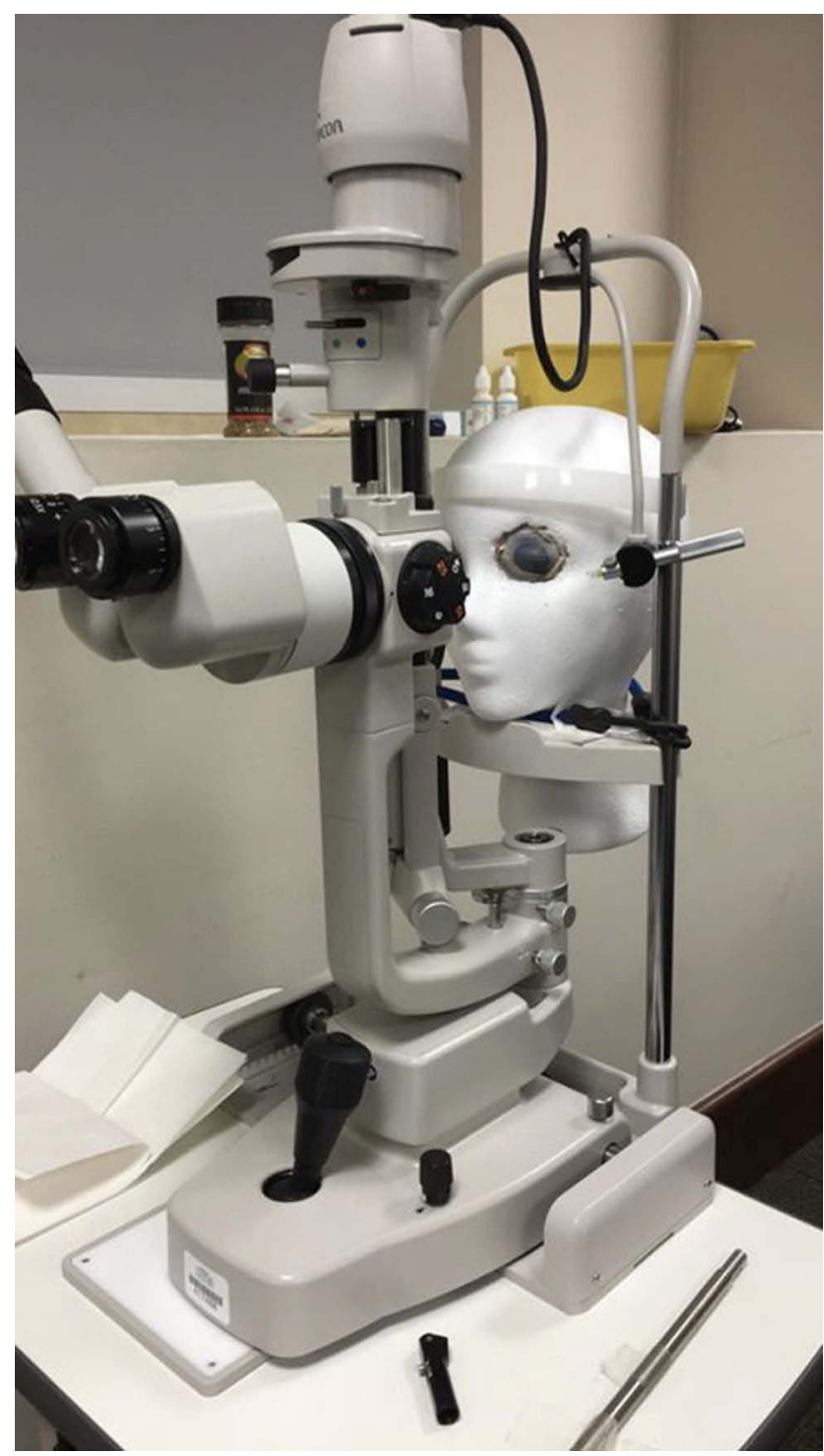

Figure 2 The example of the harvested cow eye and styrofoam head models mounted in the Slit-Lamp.

\section{Station 2}

Figure 4. This was the iCare Tonometer station. This station required a table, two chairs, and a Tonopen. This station had one instructor. The instructor demonstrated the use of the Tonopen for measuring eye pressure. The trainees were then divided into two groups, holders and testers. The holders held the Styrofoam heads and the testers used the Tonopen to measure eye pressure. The holders and testers then switched roles to allow all trainees the opportunity to use the Tonopen. The instructor provided direction to each individual in order to improve trainee proficiency.

\section{Station 3}

Figure 5. This was the Slit-lamp station. This station required one Slit-Lamp, one chair, one bungee cord,
Fluorescence strips, hollow-bore needles (18-G, 20-G and 25-G) and one Algerbrush II burr. This station had one instructor. The instructor demonstrated the general use of the Slit Lamp followed by how to view a CFB. The Slitlamp did have the instructor's lens attachment, which allowed for more specific individual instruction. The instructor then demonstrated how to place Fluorescence on the cow eye and demonstrated the use of the ophthalmological burr and the hollow-bore needle for CFB removal. As each trainee took individual turns using the Slit lamp, the instructor used a bungee cord to mount each trainee's Styrofoam head into the slit-lamp chin rest. Each trainee was given the opportunity to use the different aspects of the Slit-Lamp and then used the burr and the hollow-bore needles to remove CFBs. The instructor provided individual direction to improve trainee proficiency.

\section{Station 4}

Figure 6. This was the Wood's lamp station. This station required one table, two chairs, a Woods Lamp, hollow-bore needles (18-G, 20-G and 25-G), an Algerbrush II burr. This station had one instructor. The instructor demonstrated how to place Fluorescence on the cow eyes, and demonstrated how to view a CFB. Then, the instructor demonstrated how to use the burr and hollow-bore needles to remove a CFB. The trainees were divided into two groups, testers and holders. The holders held a Styrofoam head face up on the table. The testers used the Woods lamp to visualize the CFBs followed by using the hollow-bore needles and burr for $\mathrm{CFB}$ removal. The trainees alternated between being holders and testers. The instructor provided individual direction to improve trainee proficiency.

\section{Results}

Sixteen emergency medicine residents (PGY 1-3) participated in this simulation. Concerning the post-simulation course evaluation, $100 \%$ of participants indicated that this curriculum should be an annual simulation. $87 \%$ of participants felt this was a highly realistic simulation with $12.5 \%$ indicating this was fairly realistic. No participants felt this was an unrealistic simulation. The Pre-Sim and Post-Sim self-assessments were written as a Likert rating scale. These responses focused on the individual's selfperception of his/her competency and confidence with the use of the iCare Tonometer, Slit Lamp, Woods Lamp, and hollow-bore needles \& ophthalmologic burrs for CFB removal. Given that Likert scales can be controversial to interpret, a general statement can be made that the overall 


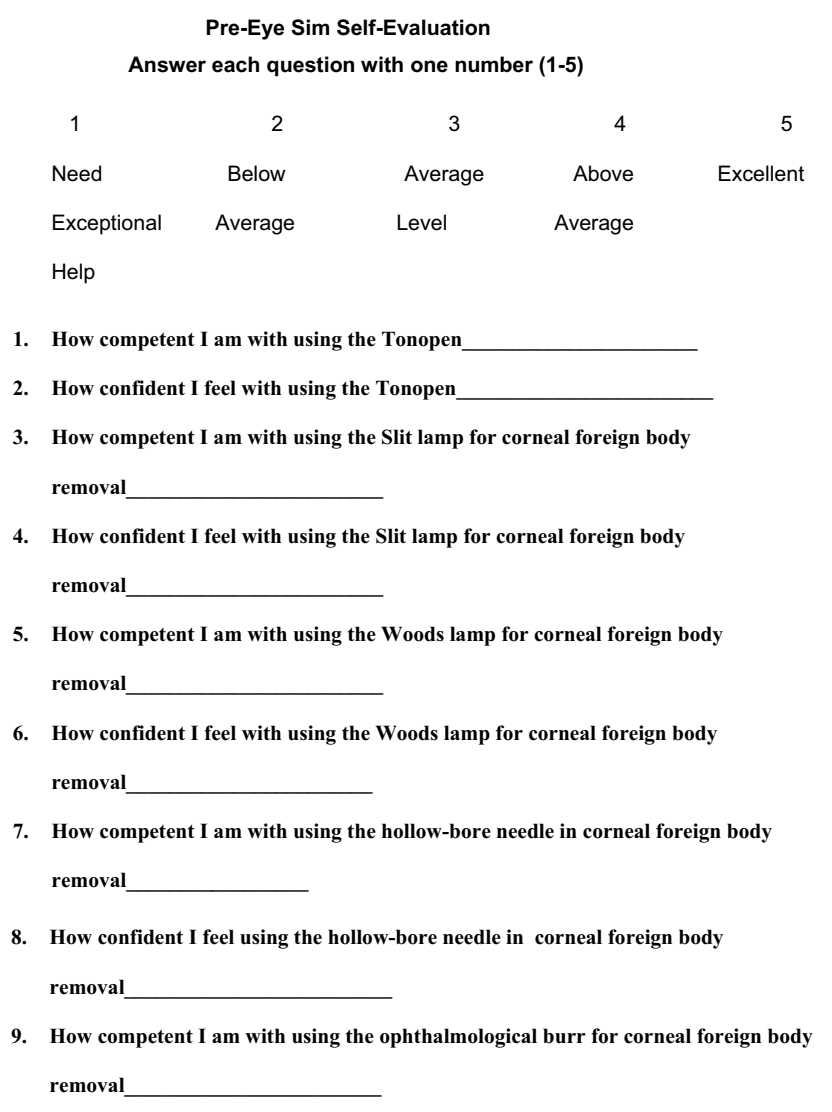

10. How confident I feel with using the ophthalmological burr for corneal foreign body removal

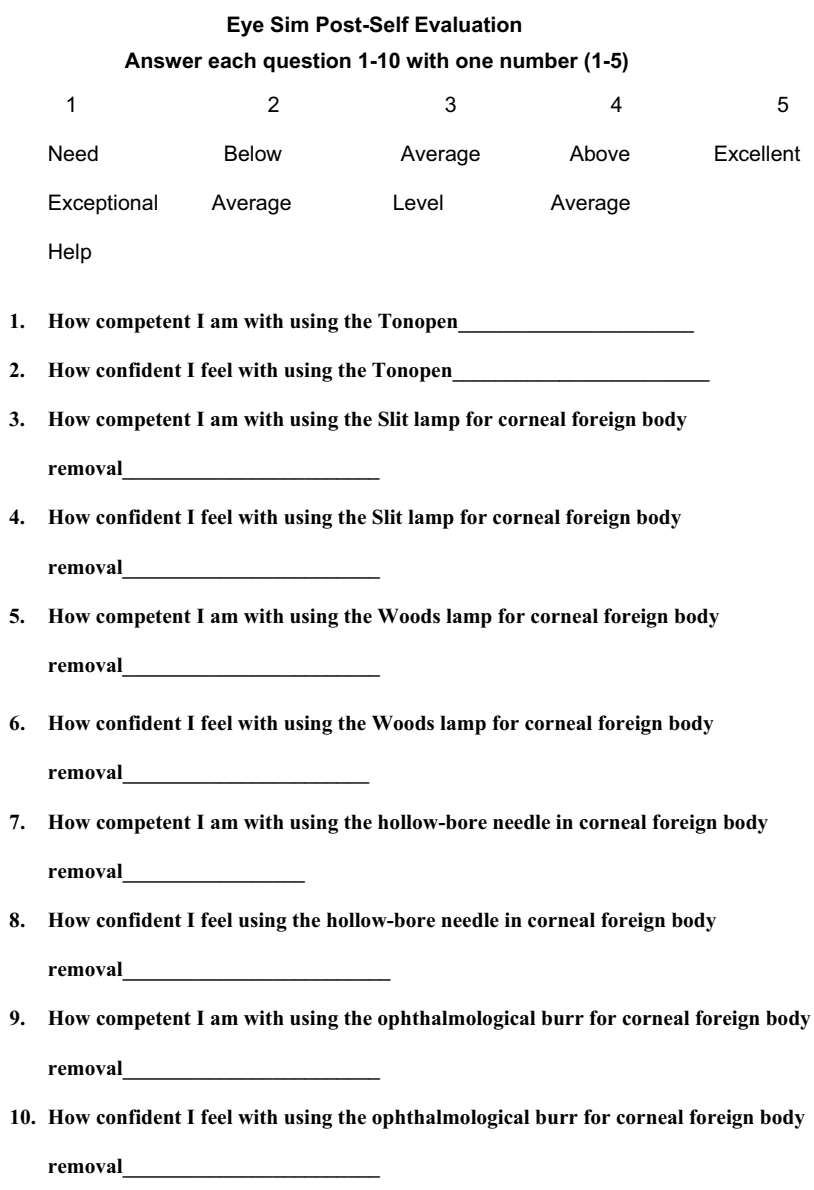

Eye Sim Post-Self Evaluation 5 t

1. How competent $I$ am with using the Tonopen

2. How confident I feel with using the Tonopen

3. How competent I am with using the Slit lamp for corneal foreign body

remova

4. How confident I feel with using the Slit lamp for corneal foreign body

removal

5. How competent I am with using the Woods lamp for corneal foreign body

removal

6. How confident I feel with using the Woods lamp for corneal foreign body

removal

7. How competent $I$ am with using the hollow-bore needle in corneal foreign body

removal

8. How confident I feel using the hollow-bore needle in corneal foreign body

remova

9. How competent I am with using the ophthalmological burr for corneal foreign body

removal

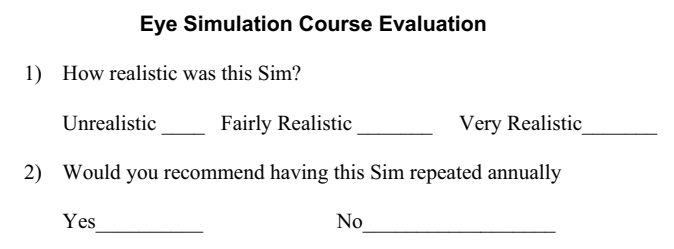

Figure 3 The Pre-Sim self-assessment, Post-Sim self-assessment, and course assessment.

responses indicated improvement in self-perception of confidence and competency with the use of the Slit-lamp, Wood Lamp, Tonopen and CFB removal with the burr and hollow-bore needle (Figure 7).

\section{Discussion}

Given ocular emergencies are a common presenting complaint in United States emergency departments, ${ }^{1-3}$ training Emergency Medicine residents in the appropriate use of common ophthalmologic equipment for eye assessment and training for CFB removal should be an essential part of quality Emergency Medicine education. This curriculum was developed based upon a needs assessment survey targeted at the University of Alabama at Birmingham PGY 1-3 Emergency Medicine residents. Based upon the results of this survey, the course objectives were established. The overall objective was to enhance ophthalmological training through simulation. The specific objectives were focused on two main areas: (1) training in the general use of the Slit Lamp, the Woods lamp, and the Tonopen, and (2) expanding knowledge and gaining familiarity with different techniques for CFB removal.

In order to create this simulation to meet the set objectives, I conducted a personal review of the literature for guidance and found several eye simulation curricula. ${ }^{10-16,18}$ However, the curricula uncovered did not focus on developing competencies in the use of common ophthalmological equipment (iCare Tonometer, Woods Lamp, Slit Lamp, ophthalmologic burr), so no guide for the development of this simulation was uncovered, and no comparison data can 


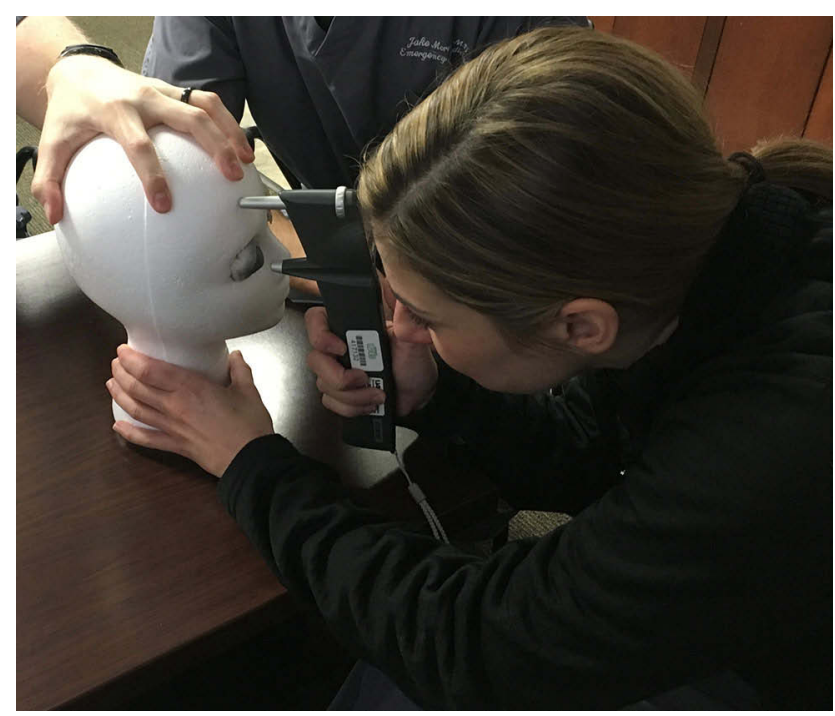

Figure 4 The iCare Tonometer station.

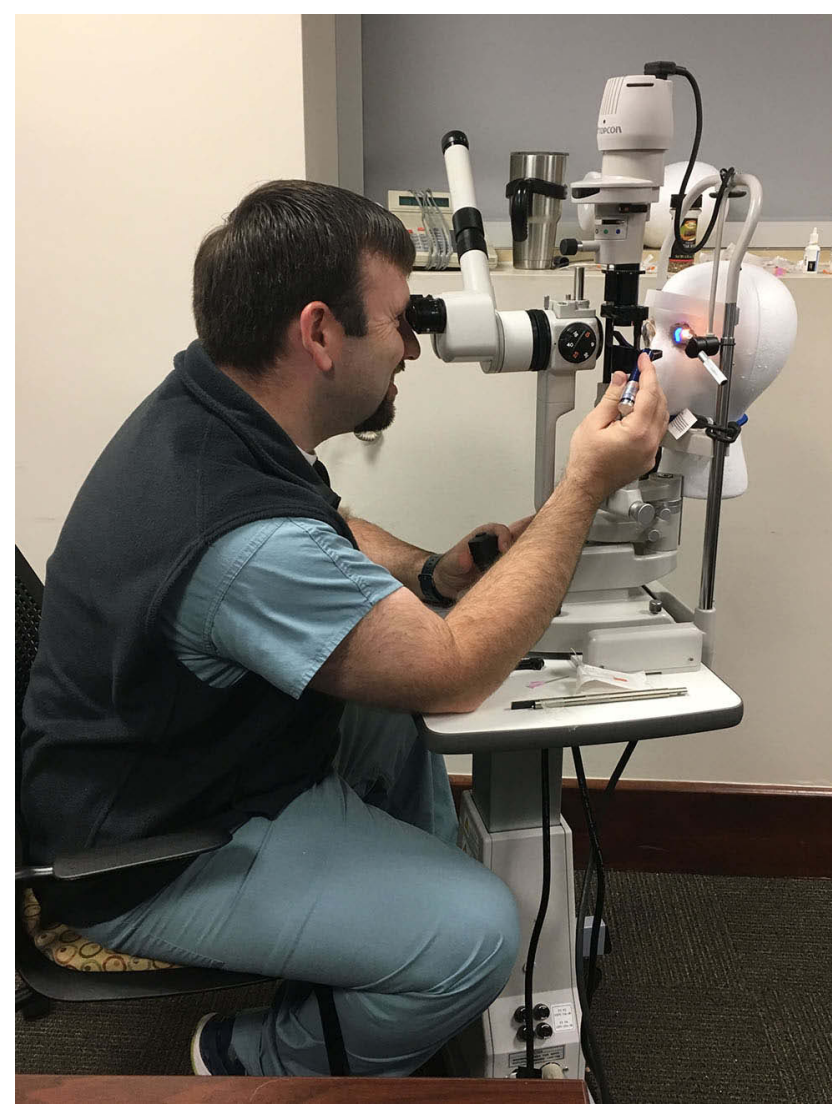

Figure 5 The Slit-Lamp station.

be provided. In addition, my literature search concerning curricula for CFB removal revealed curricula that lacked realism due to unusual artificial eye models and the uncommon CFBs. ${ }^{10-14}$ These previous eye models have been

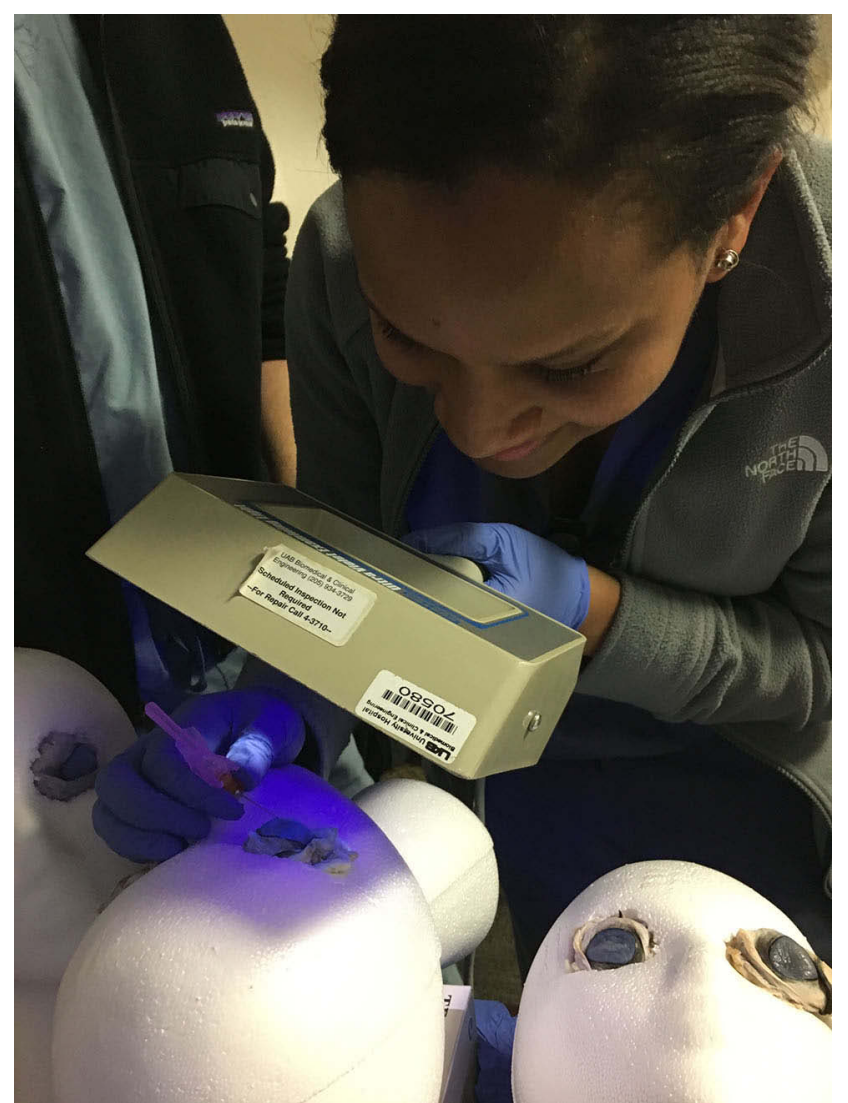

Figure 6 The Wood's Lamp station.

created out of agar trays, gel/plastic combinations, glass spheres, and cardboard. One eye simulation used bovine eyes as the realistic eye model, but that simulation was for the study of pressure changes in different parts of the interior eyeball wall ${ }^{15}$ instead of CFB removal. In addition, the previously described materials used for CFBs have included wax, ground pepper, peppercorn, mustard seeds, and even tarantula hairs..$^{10,12-14,16}$ Though these are possible CFBs, metal grinds as CFBs would be more realistic given these are common industrial injuries. ${ }^{17}$ The metal grind CFBs have been described in a previous eye simulation, ${ }^{18}$ but in that simulation, the corneas were made from silicone and cornstarch. Not only are these models unrealistic, but it would be a challenge to place these models in a Slit-lamp or obtain a realistic experience when using the Woods lamp or iCare Tonometer.

Given my literature search for curricula focused on teaching proficiency with operating common ophthalmologic equipment using realistic eye models with true-tolife CFBs did not provide effective guidance, I created this novice simulation. To create realistic eye models, harvested bovine eye was purchased. A metal grinder was 


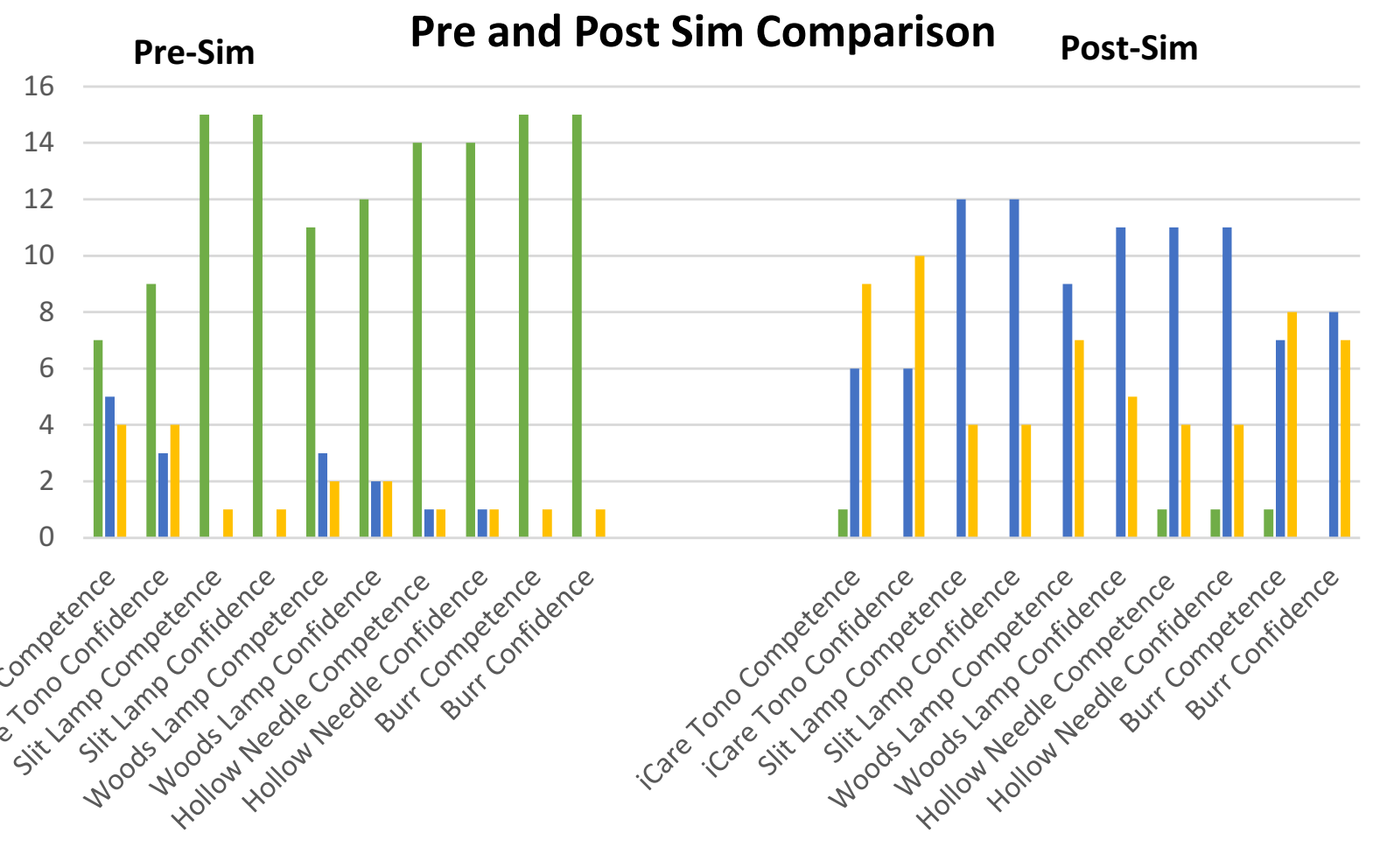

Level 1 and 2: Below average

Figure 7 The Pre-Sim and Post-Sim self-assessment results.

used to cause metal grinds/fragments to adhere to the cow eye corneas. Then, these eyes were placed in the eye sockets of Styrofoam heads. Thus, realistic eye models were created. These models could easily be mounted in a Slit lamp with a bungee cord or held for use with a Woods lamp and with the Tonopen. Based on the Preand Post-Sim self-assessments, this curriculum was successful in reaching the established goals of acquiring hands-on experience with the use of general ophthalmological equipment and expanding knowledge and skill with different techniques for CFB removal.

This curriculum represents one option for the beginning phases of an ocular emergency medicine curriculum. As indicated in the self-assessments, a major strength of this curricula is the simplicity of a hands-on experience with the freedom to learn the equipment and CFB removal techniques without the stress of having to pass a competency test resulted in the trainees developing confidence and a selfassessed competency. The limited number of trainees and the fact that the trainees did not have an objective assessment of their skill development are the weakness of this course. For future expansion and globalization of this curriculum and to establish reliability and validity, more than
16 trainees will need to be involved. In addition, follow-up simulations will need to be undertaken with a focus on the assessment of competency by an objective and experienced Board-Certified Emergency Medicine physician, ophthalmologist, or optometrist. For future simulations, the study design will need to create a questionnaire that can be used to assess individual competency as determined by an objective qualified evaluator.

\section{Conclusion}

This cost-effective and realistic eye simulation curriculum uses harvested cow eye models with metal-grind corneal foreign bodies to teach the use of common eye assessment equipment and teach techniques for corneal foreign body removal. This course can be used as a basic introduction to any ocular emergency medicine curriculum.

\section{Acknowledgment}

This paper was presented at The Society of Academic Emergency Medicine 2017 in Orlando, Florida as an abstract presentation with interim findings. Thompson, LB: A Cow Eye, A Burr, and a Student Have What in Common? 
A Realistic Eye Simulation Curriculum. Academic Emergency

Medicine. 2017; 24: S1 (S287).

\section{Disclosure}

The author reports no conflicts of interest in this work.

\section{References}

1. Channa R, Zafar SN, Canner JK, Haring RS, Schneider EB, Friedman DS. Epidemiology of eye-related emergency department visits. JAMA Ophthalmol. 2016;134(3):312-319. doi:10.1001/jamaophthalmol. 2015.5778

2. Weiss AJ, Wier LM, Stocks C, Blanchard J Overview of Emergency Department Visits in the United States,2011: Statistical Brief \#174. Healthcare Cost and Utilization Project (HCUP) Statistical Briefs [Internet]. Rockville (MD): Agency for Healthcare Research and Quality (US); 2006-2014 Jun.

3. Reichman E. Emergency Medicine Procedures. Chapter 159: Corneal Foreign Body Removal. 2nd ed. McGraw-Hill Education/Medical; 2013.

4. Mottow-Lippa L. Ophthalmology in the medical school curriculum: reestablishing our value and effecting change. Ophthalmology. 2009;116:1235-1236, 1236 e1. doi:10.1016/j.ophtha.2009.01.012

5. Jacobs DS. Teaching doctors about the eye: trends in the education of medical students and primary care residents. Surv Ophthalmol. 1998;42:383-389. doi:10.1016/S0039-6257(97)00121-5

6. Quillen DA, Harper RA, Haik BG. Medical student education in ophthalmology: crisis and opportunity. Ophthalmology. 2005;112:1867-1868.

7. Chan TY, Rai AS, Lee E, et al. Needs assessment of ophthalmology education for primary care physicians in training: comparison with the International Council of Ophthalmology recommendations. Clin Ophthalmol. 2011;5:311-319. doi:10.2147/OPTH.S17567

8. Sun D, Hussain A, Tebbal A, et al. National survey of the management of eye emergencies in the accident and emergency departments by senior house officers: 10 years on - has anything changed? Emerg Med J. 2008;25:76-77. doi:10.1136/emj.2007.049999
9. Yeung A, Yeung J, Ashraf N, et al. Ophthalmic skills-confidence and knowledge of recently graduated doctors. Acta Ophthalmol. 2008;85.

10. Austin PE, Ljung M, Dunn KA. A new model for teaching corneal foreign body removal. Acad Emerg Med. 1995;2:831-834. doi:10.1111/acem.1995.2.issue-9

11. Truong K, Janssen A, Moore C, LaBond V. 326 use of a didactic low fidelity simulated model to measure objective improvement in corneal foreign body removal. Ann Emerg Med. 2016;68(4):125-126. doi:10.1016/j.annemergmed.2016.08.342

12. Marson BA, Sutton LJ. The Newport eye: design and initial evaluation of a novel foreign body training phantom. Emerg Med J. 2014;31:329-330.

13. Gallagher K, Lin PF, Koukkoulli A, Puertas R, Okhravi N. "Lowtech" simulation of corneal foreign body removal. Can J Ophthalmol. 2016;51(5):386-389. doi:10.1016/j.jcjo.2016.03.016

14. Cheng ML, Fu L, Cackett P. A novel, safe and cost effective way for teaching corneal foreign body removal. Emerg Med J. 2015;32 (6):501-502. doi:10.1136/emermed-2014-204545

15. Yan-Hui C, Ju-Fang H, Si-Ying C, et al. Study on establishment and mechanics application of finite element model of bovine eye. BMC Ophthalmol. 2015;15(1):1-16. doi:10.1186/1471-2415-15-1

16. Yelin Y, Ted C, Kamiar M. Acute conjunctivitis and corneal foreign bodies secondary to tarantula hairs. CMAJ. 2016;188(3):212-214. doi:10.1503/cmaj.150571

17. Sayegh JS, Lahham S, Woodhouse L, Seong J, McCoy CE. Creation of a realistic model for removal of a metallic corneal foreign body for less than \$75. West J Emerg Med. 2017;18(1):121-125. doi:10.5811/ westjem.2016.10.32234

18. Ramakrishnan T, Constantinou M, Jhanji V, Vajpayee RB. Corneal metallic foreign body injuries due to suboptimal ocular protection. Arch Environ Occup Health. 2012;67:1, 48-50. doi:10.1080/ 19338244.2011.573023
Advances in Medical Education and Practice

\section{Publish your work in this journal}

Advances in Medical Education and Practice is an international, peerreviewed, open access journal that aims to present and publish research on Medical Education covering medical, dental, nursing and allied health care professional education. The journal covers undergraduate education, postgraduate training and continuing medical education

\section{Dovepress}

including emerging trends and innovative models linking education, research, and health care services. The manuscript management system is completely online and includes a very quick and fair peer-review system. Visit http://www.dovepress.com/testimonials.php to read real quotes from published authors. 